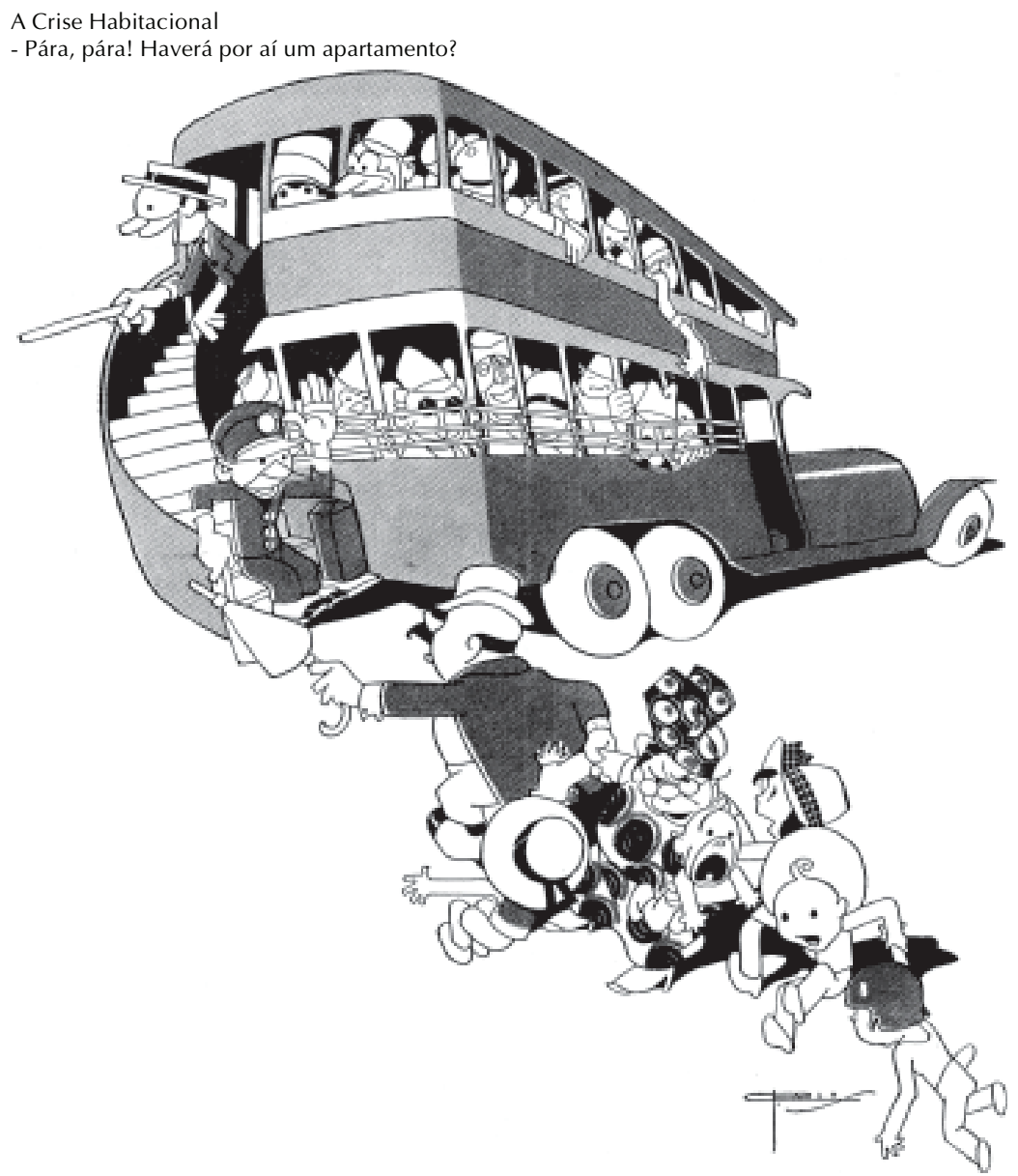

J. Carlos. Para Todos. Publicado em 05/05/1928. Reprodução; História da Caricatura no Brasil, Herman Lima, Livraria José Olympio Editora, 1963, v. 2, p. 453. 


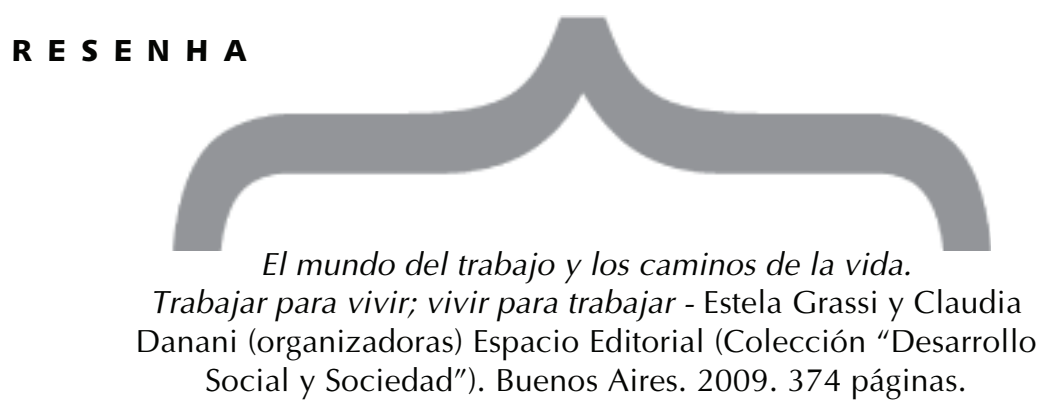

\section{Para pensar sobre o Mundo del Trabajo y los Caminos de la Vida}

Norberto Alayón ${ }^{*}$

El libro que reseñamos declara desde el título su intención. El mundo del trabajo y los caminos de la vida, al enunciar que en nuestras sociedades la mayoría de las personas vive de su trabajo, anuncia que en esa intersección hay una unidad y allí se paran las autoras para hablar de la sociedad, no en abstracto, sino de aquella que emergió de la inundación de liberalismo de mercado, que se llevó en sus terribles corrientes y tempestades una buena parte de las seguridades, protecciones e igualitarismos que, aunque con enormes debilidades, existían en el país. Sin embargo, en ese enunciado las autoras anuncian, también, que se apartan de los estudios centrados en poblaciones o grupos con problemas de trabajo y sin ocupación porque, dicen, el "desafío es elucidar las consecuencias del hecho de que hasta la exclusión del mundo del trabajo sea ya una condición posible en la sociedad del trabajo, y no fuera de ella". Es decir, la sociedad en la que trabajar

"Profesor titular de la carrera de Trabajo Social de la Universidad de Buenos Aires, director de la colección "Desarrollo Social y Sociedad" de Editorial Espacio de Buenos Aires. Dirección postal: Marcelo T. de Alvear, 2230, Capital Federal, CP: C1122AAJ, Buenos Aires, Argentina. Correo eletronico: nalayon@mail.fsoc.uba.ar. 
devino un valor en sí mismo, la principal amalgama, el hecho social total - según la noción acuñada por Marcel Mauss - pero también en la posibilidad de no sobrevivir si se desconsidera que sólo las normas hacen posible la vida social.

Ese es el lugar, entonces, desde donde se plantean las preguntas (o, mejor dicho, los problemas) de una investigación que las lleva hacia las más diversas formas de ocupación e inserción laboral y a tomar como fuente primaria de datos los relatos que hacen de sus vidas de trabajo las personas entrevistadas. Son situaciones, condiciones y experiencias disímiles las que atraviesan o han atravesado cada una de ellas. Algunas están contratadas por el régimen "normal" de tiempo indeterminado y protegidos por la seguridad social; hay empleados en puestos de alta performance, y otros que disponen de una mínima calificación; hay empleados bajo las nuevas modalidades de contratación flexibles; también trabajadores autónomos e informales; y hasta desempleados con planes sociales por los que deben contraprestar trabajo. Cada uno de los capítulos aborda la pregunta acerca de ¿cómo se trabaja y vive hoy? desde la perspectiva que brinda cada uno de estos diferentes lugares del mundo del trabajo. En cada uno se reconoce las vidas de trabajo que emergen de las transformaciones político-culturales e institucionales ocurridas en el tránsito hacia este siglo y que se hacen más visibles y definidas cuando, como dicen las autoras, se aquietan las aguas después de aquella inundación. Sin embargo, si esos relatos son la fuente y la perspectiva con las que construyen los datos, estas investigadoras se asoman al mundo de la vida no para repetir "el punto de vista del actor", sino para comprenderlo y para mejor comprender esas transformaciones, porque entienden (y tienen como un supuesto del análisis) que este mundo "no es ajeno a la estructuración (de la sociedad) por el trabajo, sino parte (...) de su real dominio... al mismo tiempo que "los hechos y sucesos sociales (...) cobran sentido para el sujeto desde lo que para él es un mundo singular, y es en relación con esos sentidos que se toman decisiones y desarrollan acciones referidas "al trabajo". Al menos una parte de las "buenas razones" por las que trabajamos - nos dicen - remiten o encuentran su justificación en esta esfera de la vi$\mathrm{da}$, lo que no quiere decir que sean producidas con independencia de los procesos socio-culturales, sino al contrario: en estos procesos "trabajar por el propio interés o para no morirse de hambre" pueden constituirse en los parámetros en los que se inscribe la "razonabilidad" de las prácticas.

Es interesante este enfoque, porque la división entre fuerza de trabajo y trabajador, sobre la que se instituyó el capitalismo, habilitó la preservación de un tiempo y un espacio de la vida fuera del trabajo, vivida como "privada", asunto de cada cual. La separación trabajo y vida como manifestación de la diferenciación de los ámbitos de la producción y de la reproducción, encuentra su justificación en el principio de libertad de las personas, pero solapa, al mismo tiempo, el hecho de que vida y reproducción son inmediatamente condiciones y requisitos de la existencia de la sociedad (como comunidad política y sistema económico). Relación a la que equivale la obligación-necesidad de trabajar y los derechos que preservan la posibilidad y las condiciones para hacerlo. Es decir, en la objetivación de la esfera del trabajo, y en la preservación de la vida privada del sujeto se hallan, simultáneamente, el reconocimiento de su ser plural y autónomo, y también la génesis 
de la subalternización de la vida más allá del trabajo y de la subjetivación de las necesidades.

¿Cómo se despliega el análisis, entonces? En el primer capítulo, la referencia es el "empleo normal"; es decir, acordado en una relación formal por tiempo indeterminado. En este caso, Grassi y Danani empiezan por esas condiciones que, aún manteniéndose como la regla y referencia de las modalidades irregulares, transitorias y precarias de empleo, se materializa en normalidades que desbordan lo común de las normas, al punto de acercar algunas vidas a la experiencia de la precariedad. Las autoras se detienen en la contingencia de lo que deviene normal en nuestras sociedades, tema que retoman en el capítulo final de las conclusiones del libro.

Florencia Luci tiene a su cargo el segundo capítulo y se ocupa de situaciones escasamente consideradas por la literatura especializada: la de los asalariados de altos puestos; allí, son las estrategias de carrera las que son analizadas, así como lo que la autora titula "la gestión de sí": las reglas están y se invisibilizan al mismo tiempo, y el acierto en las decisiones conlleva una importante cuota de incertidumbre, aún en las mejores condiciones.

En un lugar y condiciones distantes, en los capítulos siguientes, Claudia Cabrera, Paula L. Aguilar, y Malena Hopp, tienen a la vista vidas que transcurren en la precariedad y la mayor incertidumbre. Historias de trabajos siempre desprotegidos, fuera de las normas e informales moldean las experiencias que toma como referencia Cabrera en el capítulo 3, haciendo ver con qué recursos se construyen los parámetros de valoración de los empleos y las expectativas que se asocian al trabajo. Por su parte, Aguilar, en el capítulo 5, pone en evidencia que algunos no pueden parar de trabajar aún cuando, por períodos, no encuentren qué hacer, porque no están sujetos a ningún dispositivo que los amarre al mundo; el futuro (el retiro obligado de la vida activa) es pura incertidumbre para estas personas. Y Malena Hopp hace lo propio, en el capítulo 6, con los efectos de los planes sociales con contraprestación laboral, los que, más allá de la intencionalidad inmediata de la política, cargan con el estigma de ser asistencia para quienes no se les reserva un lugar en el mundo del trabajo reconocido como tal.

El capítulo 5, a cargo de Sandra Guiménez, pone en evidencia las consecuencias de relaciones laborales precarias en el seno del Estado por medio de contratos de locación de servicios que ocultan una relación asalariada, no sólo para la vida de las personas involucradas, sino por el tipo de conflictos que se generan, en desmedro del servicio estatal.

Por su parte, Maitena Fidalgo desarrolla el capítulo 7, referido a las estrategias frente a los riesgos y contingencias de la vida, cuando han ocurrido dos procesos simultáneos: la fragmentación del mercado de trabajo, que dejó fuera de la seguridad social a casi la mitad de la población trabajadora, al mismo tiempo que se cuestionó la validez y legitimidad de esas instituciones. Si en el último año hay un retorno y recuperación de estas últimas, no ocurre lo mismo con aquella fragmentación, por lo que amplios sectores se mantienen con escasísimos resguardos institucionales ante los problemas de la salud, la invalidez o el retiro de la actividad laboral.

Finalmente, en el último capítulo del libro, Danani y Grassi retoman las propuestas generales del libro. Allí, vale la pena detenerse una vez más en sus obser- 
vaciones de índole metodológica. Ellas dicen que no pretendieron mostrar la diversidad, porque ésta es una cualidad ineludible de la vida social y, por lo tanto, está dada como un supuesto de sus estudios. En cambio, reafirman que intentaron hurgar en la unidad de condición entre experiencias tan variadas, cuando el trabajo ha cambiado, y no porque alguna vez haya estado estático, sino porque por décadas se había avanzado en la conformación de instituciones que permitieron a los trabajadores proyectar y proyectarse incluso en las generaciones futuras. Luego del cuestionamiento de esa seguridad, cuando las aguas se aquietaron, es que asoma nuevamente un mundo más incierto y que exige estar más disponible.

Hay que decir, por último, que en sus análisis, las autoras nunca quedan afuera de su problema de estudio: se incluyen como otras tantas personas del mundo de trabajo, sin caer nunca en la subjetivación inocente del problema. Y es así porque no dejan de prestar atención, y de compartir con el lector, las tentaciones que acechan a los estudios sociales (el realismo de los datos, la mera denuncia, la desconsideración de la capacidad reflexiva de las personas como falsa conciencia) y de las que ellas no se sienten ajenas, sino preocupadas por evitarlas.

Aunque de escritura variada, y de complejidad analítica también dispar, el libro guarda una unidad que pone en evidencia el trabajo de equipo. Vale la pena su lectura, por lo que nos informa, por la originalidad del enfoque, y por las hipótesis que pueden abrirse y que es de esperar que este equipo continúe investigando.

\section{REFERÊNCIAS BIBLIOGRÁFICAS}

GRASSI, Estela y DANANI, Claudia (org.). El mundo del trabajo y los caminos de la vida. Trabajar para vivir; vivir para trabajar. (Colección "Desarrollo Social y Sociedad"). Buenos Aires: Espacio Editorial, 2009. 374 p.

Recebido em 20 de março de 2009.

Aceito para publicação em 10 de abril de 2009. 